\title{
UPAYA PENINGKATAN KUALITAS HIDUP LANSIA DENGAN SENAM KAKI, AKUPRESUR DAN HOME CARE MELALUI POS PEMBINAAN TERPADU (POSBINDU)
}

\author{
Martaulina Sinaga ${ }^{1}$, Adelina Sembiring ${ }^{2}$, Zuraidah $^{3}$ \\ ${ }^{1}$ STIKes Mitra Husada Medan \\ ${ }^{2}$ STIKes Mitra Husada Medan \\ ${ }^{3}$ STIKes Mitra Husada Medan \\ martaulina78@gmail.com, adelinasembiring91@gmail.com, zuraidahsir@gmail.com
}

\begin{abstract}
Abstrak
Manusia yang telah memasuki tahap akhir dari fase kehidupan adalah kelompok lansia yang telah mencapai usia 60 tahun keatas. Ditinjau dari kesehatan kelompok lansia akan mengalami penurunan derajat kesehatan baik secara alamiah maupun akibat penyakit. Penyakit yang sering dialami lansia adalah hipertensi, dan ketidakmampuan fisik (osteoarthritis). Tujuan kegiatan yang dilakukan terhadap lansia di Kelurahan Simalingkar B dengan melakukan senam kaki, akupresur dan home care melalui posbindu. Hasil kegiatan home care lansia yang terbanyak pada usia 66-70 tahun dengan jumlah 12 responden (40\%) dan jenis kelamin perempuan 23 responden (76,67\%). Pengetahuan lansia tentang senam sebelum dilakukan edukasi mayoritas cukup sebanyak 17 responden $(56,7)$ dan sesudah dilakukan edukasi berpengetahuan cukup 18 responden $(60 \%)$ dan berpengetahuan baik 12 responden (40\%). Tekanan darah sistolik sebelum dilakukan senam kaki mayoritas $130 \mathrm{mmHg} 14$ responden $(46,7 \%)$ dan setelah senam kaki mayoritas tekanan darah sistolik $135 \mathrm{mmHg}$ sebanyak 12 responden (40\%). Tekanan darah diastolik sebelum dilakukan senam kaki mayoritas $80 \mathrm{mmHg} 26$ responden $(87,0 \%)$ dan setelah senam kaki mayoritas tekanan darah sistolik $80 \mathrm{mmHg}$ sebanyak 23 responden $(76,6 \%)$. Senam kaki berpengaruh kepada tekanan darah. Ada perbedaan perubahan skor kualitas tidur sebelum dan sesudah pemberian terapi akpresur pada lansia osteoartritis
\end{abstract}

Kata Kunci : Akupresur, Home Care, Senam Kaki

\section{PENDAHULUAN}

Manusia yang telah memasuki tahap akhir dari fase kehidupan adalah kelompok lansia yang telah mencapai usia 60 tahun keatas. Ditinjau dari kesehatan kelompok lansia akan mengalami penurunan derajat kesehatan baik secara alamiah maupun akibat penyakit (Stanhope, M., \& Lancaster, J, 2016)

Menurut data di Indonesia, diperkirakan jumlah lansia pada tahun 2020 (27.08 juta), tahun 2025 (33.69 juta) dan tahun 2035 (48.19 juta).
Menurut Badan Pusat Statistik Sumatera Utara proporsi lansia bertambah secara nyata yaitu meningkat dari 7,58 \% pada tahun 2018 menjadi 7,87 \% pada tahun 2019 atau meningkat 0,29\%. (Kemenkes RI, 2020)

Penyakit yang sering dialami lansia adalah hipertensi, (Riskesdas, 2018), dan ketidakmampuan fisik (osteoarthritis) (Ambardini, 2019). Penyakit ini bersifat kronik, berjalan progresif lambat, tidak meradang, dan ditandai oleh adanya deteriorasi rawan sendi dan adanya pembentukan tulang baru pada permukaan sendi (Carter, 2015). Serangan 
nyeri yang terus menerus dapat menimbulkan kelemahan sehinga mereka tidak mampu melakukan kegiatan sehari-hari, akibatnya lansia menjadi tidak produktif. Oleh karena itu perlu penatalaksanaan segera pada lansia dengan nyeri osteoartritis setelah keluhan utama muncul (Sahar, 2018).

Salah satu tujuan penanganan osteoartritis adalah mengontrol nyeri, untuk mencapai tujuan tersebut, dilakukan pendekatan melalui tehniktehnik meredakan nyeri tanpa obat, pengobatan untuk mengontrol nyeri, pembedahan, terapi komplementer dan alternatif (Dewi, 2009). Pengelolaan osteoartritis terdiri dari terapi nonfarmakologi, terapi farmakologis dan terapi bedah. Terapi bedah diberikan apabila terapi farmakologis dan non farmakologis tidak berhasil untuk mengurangi rasa sakit (Soeroso, 2016).

Salah satu terapi non farmakologi yang dapat dilakukan perawat secara mandiri dalam menurunan tingkat nyeri osteoartritis lutut adalah akupressur (Kurniawan, 2014). Akupresur merupakan pengembangan dari teknik akupuntur. Pada terapi akupresur dan akupuntur tehnik dasar yang digunakan pada dasarnya sama. Hanya saja dalam pelaksanaannya akupresur menggunakan jarijari tangan (Hartati, 2012).

Akupresur adalah salah satu terapi komplementer yang secara legal tercantum dalam permenkes RI nomor 1109/Menkes/Per/2007 (Zahrawani, 2010). Akupresur merupakan terapi komplementer jenis non-invasif (McGuire, 2006). Akupresur bisa memblok area yang menterjemahkan nyeri. Dilakukannya akupresur ini dapat merangsang senyawa endorphin untuk keluar lebih banyak. Senyawa ini berkontribusi dalam mengurangi rasa sakit atau nyeri sehingga keluarnya senyawa endorphin yang semakin banyak dapat menurunkan kejadian nyeri (Davis, Eshelman, \& McKay, 1995).

Hipertensi pada lansia dapat dilakukan secara promotif, preventif, dan kuratif. Senam pada lansia adalah salah satu cara preventif yang mudah dilakukan dan tidak memberatkan. Senam lansia membantu tubuh agar tetap bugar dan tetap segar karna melatih tulang tetap kuat, mendorong jantung bekerja optimal dan membantu menghilangkan radikal bebas yang berlebihan didalam tubuh

Berdasarkan hasil wawancara dengan kader

lansia di Kelurahan Simalingkar B Kecamatan
Medan Tuntungan dan pemeriksaan kesehatan pada lansia didapatkan bahwa banyak lansia yang mengalami hipertensi dan keluhan nyeri pada sendi yang disebabkan karena oleh pola hidup yang tidak sehat dan banyak lansia tidak memanfaatkan fasilitas pelayanan Kesehatan.

Parellangi, (2018) home care adalah : layanan kesehatan yang dilakukan oleh profesional di tempat tinggal pasien (dirumah) dengan tujuan membantu memenuhi kebutuhan pasien dalam mengatasi masalah kesehatan yang dilaksanakan oleh tim kesehatan profesional dengan melibatkan anggota keluarga sebagai pendukung didalam proses perawatan dan penyembuhan pasien sehingga keluarga bisa mandiri dalam mengatasi masalah kesehatannya

Upaya yang dilakukan pada lansia di Kelurahan Simalingkar B dengan melakukan senam kaki, akupresur dan home care melalui posbindu .

\section{METODE}

Kegiatan pengabdian dilaksanakan tiga tahap. Tahap 1 adalah identifikasi masalah pada lansia yang dilakukan dengan wawancara kepada tokoh masyarakat, kader lansia, dan lansia. Pemeriksaan kesehatan dan mengidentifikasi pengetahuan lansia tentang senam lansia khususnya senam kaki. Pada tahap didapatkan data bahwa dari 30 lansia yang diperiksa dan diwawancarai terdapat 20 yang menderita hipertensi dan jarang ke tempa pelayanan lansia. Pengetahuan tentang kaki pada lansia diukur dengan menggunakan angket yang berisi 10 pertanyaan.

Tahap 2 adalah tahap pelaksanaan. Tahap ini peneliti memberikan edukasi kepada lansia tentang hipertensi dan mempraktekkan senam kaki yang bertujuan untuk menurunkan tekanaan darah. Gerakan senan kaki dimulai dari 1) Duduk secara tegak diatas kursi (jangan bersandar) dengan meletakan kaki dilantai. 2) Dengan meletakan tumit di lantai, jari-jari kedua belah kaki diluruskan ke atas lalu bengkokan kembali ke bawah seperti cakar dilakukan sebanyak 10 kali. 3) Dengan meletakan tumit dilantai, angkat telapak kaki ke atas.kemudian, jari-jari kaki diletakan dilantai dengan tumit kaki diangkatkan ke atas. Cara ini diulangi sebanyak 10 kali. 4) Tumit kaki diletakan 
dilantai. Bagian depan kaki diangkat keatas dan buat putaran $360^{\circ}$ dengan pergerakan pada pergelangan kaki sebanyak 10 kali. 5) Jari-jari kaki diletakan dilantai. Tumit diangkat dan buat putaran $360^{\circ}$ dengan pergerakan pada pergelangan kaki sebanyak 10 kali. 6) Kaki diangkat keatas dengan meluruskan lutut. Buat putaran $360^{\circ}$ dengan pergerakan pada pergelangan kaki sebanyak 10 kali. 7) Lutut diluruskan lalu dibengkokan kembali kebawah sebanyak 10 kali. Ulangi langkah ini untuk kaki yang sebelahnya. Kemudian lakukan pada kedua kaki secara bersamaan. Angkat kedua kaki luruskan dan pertahankan posisi tersebut, lalu gerakan kaki pada pergelangan kaki, kedepan dan kebelakang. Luruskan salah satu kaki dan angkat. Putar kaki pada pergelangan kaki. Tuliskan di udara dengan kaki angka 0 sampai 9. 8) Letakkan sehelai kertas surat kabar dilantai. Robek kertas menjadi dua bagian. Bentuk kertas itu menjadi seperti bola dengan kedua belah kaki. Kemudian, buka bola itu menjadi lembaran seperti semula dengan menggunakan kedua belah kaki. Cara ini dilakukan hanya sekali saja. (Sujianto, U, 2018).

Lansia dianjurkan untuk mempraktekkannya sendiri dirumah. Tahap ini berlangsung salama 1 bulan. Demonstrasi senam kaki dengan memutarkan video dan lansia diminta untuk mengkuti instruksi dari video dan instrukstur senam yang telah disiapkan.

Tahap 3 adalah tahap evaluasi dan rencana tindak lanjut. Melakukan diidentifikasi kembali pengetahuan dan keterampilannya tentang senam kaki pada lansia dengan memberikan angket. Hasil angket diolah dengan menggunakan aplikasi computer. Untuk tekanan darah peneliti memeriksa kembali tekanan darah lansia untuk melihat pengaruh senam kaki sebelum dan sesudah senam kaki dengan mengolah data dengan uji paired sample t-test.

\section{HASIL DAN PEMBAHASAN}

1. Analisis Univariat

Karakteristik lansia pada kegitan home care adalah

\section{Tabel 1. Karakteristik Lansia Pelaksanaan Home care di Kelurahan Simalingkar B Kecamatan Medan Tuntungan}

\begin{tabular}{|l|c|c|}
\hline \multicolumn{1}{|c|}{ Karakteritik } & Frekuensi & \% \\
\hline Umur & & \\
61-65 Tahun & 8 & 26,67 \\
66-70 Tahun & 12 & 40,00 \\
>70 Tahun & 10 & 33,33 \\
Total & $\mathbf{3 0}$ & $\mathbf{1 0 0}$ \\
& & \\
Jenis Kelamin & & \\
Laki-laki & 7 & 23,33 \\
Perempuan & 23 & 76,67 \\
Total & $\mathbf{3 0}$ & $\mathbf{1 0 0}$ \\
\hline
\end{tabular}

Dari Tabel 1 diperoleh bahwa lansia yang terbanyak pada usia 66-70 tahun dengan jumlah 12 responden $(40 \%)$ dan jenis kelamin perempuan 23 responden $(76,67 \%)$

Hasil kegiatan pengabdian masyarakat pengetahuan lansia tentang senam kaki dapat dilihat pada tabel dibawah ini :

Tabel 2. Pengetahuan Lansia tentang Senam Kaki Sebelum dan Setelah dilakukan Pengabdian Masyarakat.

\begin{tabular}{|l|l|c|c|c|c|}
\hline \multirow{2}{*}{ No } & \multirow{2}{*}{ Pengetahuan } & \multicolumn{2}{|c|}{ Sebelum } & \multicolumn{2}{c|}{ Sesudah } \\
\cline { 3 - 6 } & & f & \% & f & \% \\
\hline 1. & Baik & 5 & 16,7 & 12 & 40 \\
\hline 2. & Cukup & 17 & 56,7 & 18 & 60 \\
\hline 3. & Kurang & 8 & 26,7 & - & 0 \\
\hline & Total & 30 & 100 & & \\
\hline
\end{tabular}

Pada tabel 2 diatas pengetahuan lansia tentang senam sebelum dilakukan edukasi mayoritas cukup sebanyak 17 responden $(56,7)$ dan sesudah dilakukan edukasi lansia yang berpengetahuan cukup 18 responden (60\%) dan berpengetahuan baik 12 responden $(40 \%)$.

Table 3. Perbedaan Tekanan Darah Sistolik Sebelum dan Sesudah dilakukan Senam Kaki 


\begin{tabular}{|c|c|c|c|c|}
\hline \multirow{2}{*}{$\begin{array}{c}\text { Tekanan } \\
\text { Darah } \\
\text { Sistolik }\end{array}$} & \multicolumn{2}{|c|}{ Sebelum } & \multicolumn{2}{c|}{ Sesudah } \\
\cline { 2 - 5 } & $\mathbf{f}$ & $\%$ & $\mathbf{f}$ & $\%$ \\
\hline 130 & 14 & 46,7 & 5 & 16,6 \\
\hline 135 & 2 & 6,7 & 12 & 40,0 \\
\hline 140 & 9 & 30,0 & 2 & 6,7 \\
\hline 145 & 2 & 6,7 & 7 & 23,3 \\
\hline 150 & 3 & 10,0 & 2 & 6,7 \\
\hline Total & 30 & 100 & 30 & 100 \\
\hline
\end{tabular}

Pada tabel 3 diatas tekanan darah sistolik sebelum dilakukan senam kaki mayoritas 130 mmHg 14 responden $(46,7 \%)$ dan setelah senam kaki mayoritas tekanan darah sistolik $135 \mathrm{mmHg}$ sebanyak 12 responden (40\%).

Tabel 4. Perbedaan Tekanan Darah Diastolic Sebelum dan Sesudah dilakukan Senam Kaki.

\begin{tabular}{|c|c|c|c|c|}
\hline Tekanan & \multicolumn{2}{|c|}{ Sebelum } & \multicolumn{2}{c|}{ Sesudah } \\
Darah \\
Diastolik & f & \% & f & \% \\
\hline 70 & 4 & 13,0 & 4 & 13,3 \\
\hline 80 & 26 & 87,0 & 23 & 76,6 \\
\hline 90 & - & - & 3 & 3,1 \\
\hline Total & 30 & 100 & 30 & 100 \\
\hline
\end{tabular}

Pada tabel 4 diatas tekanan darah diastolik sebelum dilakukan senam kaki mayoritas $80 \mathrm{mmHg}$ 26 responden $(87,0 \%)$ dan setelah senam kaki mayoritas tekanan darah sistolik $80 \mathrm{mmHg}$ sebanyak 23 responden $(76,6 \%)$

\section{Analisis Bivariate}

\section{Tabel 4. Pengaruh Senam Kaki Terhadap Penurunan Tekanan Darah}

\begin{tabular}{|l|c|c|c|c|}
\hline $\begin{array}{c}\text { Tekanan } \\
\text { Darah }\end{array}$ & $\begin{array}{c}\text { Sebelum } \\
\text { mean }\end{array}$ & $\begin{array}{c}\text { Sesudah } \\
\text { mean }\end{array}$ & t-value & $\begin{array}{c}\text { p- } \\
\text { value }\end{array}$ \\
\hline Sistole & 136,00 & 133,00 & 51,265 & 0,000 \\
& 133,00 & 133,00 & & \\
\hline Diastole & 79,00 & 80,00 & 31,124 & 0,000 \\
& 80,00 & 80,00 & & \\
\hline
\end{tabular}

Hasil uji statistik sebelum dilakukan senam kaki diperoleh nilai $\mathrm{p}=0,000$, sedangkan hasil uji statistik sesudah dilakukan senam kaki diperoleh nilai $\mathrm{p}=0,000$ maka dapat disimpulkan senam kaki berpengaruh kepada tekanan darah. Dan Hasil analisis statistik dengan Wilcoxon p-value tingkat nyeri $(\mathrm{p}=0,000)$ dan kualitas tidur $(\mathrm{p}=0,000)$ menunjukkan ada pengaruh penurunan tingkat nyeri dan peningkatan kualitas tidur sebelum dan setelah pemberian terapi akupresur pada kelompok intervensi. Mann Whitney test didapatkan nilai tingkat nyeri $(\mathrm{p}=0,000)$ dan kualitas tidur $(\mathrm{p}=0,000)$, disimpulkan terdapat perbedaan perubahan tingkat nyeri dan kualitas tidur sebelum dan setelah pemberian terapi akupresur pada kelompok intervensi dan kelompok kontrol

Senam kaki merupakan latihan fisik yang dilakukan untuk meningkatkan kebugaran jasmani dan kondisi fisik lansia sehingga dapat meningkatkan kekuatan otot, daya tahan, kecepatan, keterampilan, latihan fisik ini terdiri dari 3 tahapan yaitu pemanasan, latihan inti dan pendinginan pemanasan bertujuan untuk memberi dorongan agar bersemangat, memanaskan jaringan tubuh agar tidak kaku dan mencegah cedera. Sedangkan pendinginan bertujuan untuk mencegah kekakuan otot dan nyeri otot, mengganti defisit oksigen dan mengurangi pusing setelah latihan.

Berdasarkan penelitian yang sudah peneliti lakukan pemberian pelatihan senam kaki Diabetes Melitus sangat efektif sehingga membantu meningkatkan sensitivitas kaki dan menurunkan resiko jatuh pada lansia DM, dengan prosentase efektifitas senam kaki $17,68 \%$ menurunkan resiko jatuh pada lansia dan 23,05\% meningkatkan sensitivitas kaki lansia DM (Kamariah dan Nurlinawati, 2018).

Perawat memiliki peran yang penting dalam membantu pasien menangani nyeri pasien. Perawat dapat membantu lansia yang mengalami nyeri secara sederhana hanya dengan menggunakan keterampilan interpesonal yang baik. Peran perawat adalah untuk membantu pasien lansia yang mengalami nyeri mempertahankan kenyamanannya semaksimal mungkin dan mempertahankan kualitas kehidupan yang baik (McGuire, 2016).

Menurut kolcaba (1992) konsep kenyamanan memiliki subjektif yang sama dengan nyeri. Nyeri dapat merupakan faktor utama yang menyebabkan seseorang merasakan ketidaknyamanan dan menghambat kemampuan serta keinginan individu untuk beraktivitas. Kolcaba mendefinisikan 
kenyamanan sebagai suatu sebagai suatu keadaan telah terpenuhi kebutuhan dasar manusia (Potter \& Perry 2015)

Untuk mengurangi rasa nyeri dilakukan Akupresur dengan tahapan 1) Tentukan lokasi titik KI1, KI4, KI5, KI7, KI8, LP3 kemudian berikan simulasi selama 3 menit (Tolal 18 menit). Akupresur bisa memblok area yang menterjemahkan nyeri. Dilakukannya akupresur ini dapat merangsang senyawa endorphin untuk keluar lebih banyak. Senyawa ini berkontribusi dalam mengurangi rasa sakit atau nyeri sehingga keluarnya senyawa endorphin yang semakin banyak dapat menurunkan kejadian nyeri (Davis, Eshelman, \& McKay, 1995).

\section{KESIMPULAN}

Kesimpulan dari kegiatan ini adalah 1) Senam kaki berpengaruh kepada tekanan darah. 2) Ada perbedaan perubahan skor kualitas tidur sebelum dan sesudah pemberian terapi akpresur pada lansia dengan osteoartritis

\section{UCAPAN TERIMAKASIH}

Kegiatan pengabdian terlaksana karena adanya dukungan, dan mengucapkan terima kasih kepada 1) Yayasan Mitra Husada Medan, 2) Ketua STIKes Mitra Husada Medan, 3) Lurah Kelurahan Simalingkar B, 4) Ketua Lansia Kelurahan Simalingkar B, 5) Kader Lansia Kelurahan Simalingkar B

\section{REFERENSI}

Aisyah, S. (2017). Manajemen Nyeri Pada Lansia Dengan Pendekatan Non Farmakologi. Jurnal Keperawatan Muhammadiyah, 2(1), 2017

Kamariyah, K., \& Nurlinawati, N. (2018). Pelatihan Senam Kaki Terhadap Penurunan Kadar Gula Darah Pada Lansia Penderita Kencing Manis (Diabetes Melitus) Di Puskesmas Rawasari Kota Jambi. Jurnal MEDIC (Medical Dedication), 1(1).

Kemenkes RI . Panduan pelayanan kesehatan lanjut usia pada Era Pandemi COVID19. Jakarta:

Kementerian Kesehatan RI. 2020 7. Kemenkes RI. dalam: Riset Kesehatan Dasar (RISKESDAS). Pusat data dan informasi kementrian kesehatan RI. 2018.

Padila, 2013. Buku Keperawatan Gerontik. Jakarta: Penerbit Nuha

Parellangi A, (2018). Home Care Nursing Aplikasi Praktik Berbasis Evidence-Based, Andi Yogyakarta.

Permatasari, A. A. (2020). Pengaruh Kombinasi Terapi Kinesio Taping Dan Akupresur Terhadap Penurunan Nyeri Pada Penderita Osteoarthritis Genu Lanjut Usia (Doctoral dissertation, Universitas Muhammadiyah Surakarta).

Permatasari, K. D., Ratnawati, D., \& Anggraini, N. V. (2020). Efektifitas Terapi Kombinasi.

Sujianto, U. (2018). Karya Cipta: Modul Senam Kaki Pelatihan Educator 